\title{
Tunable Mixed Oxides: Efficient Agents for the Simultaneous Trans-Esterification of Lipids and Esterification of Free Fatty Acids from Bio-Oils for the Effective Production of Fames
}

\author{
Angela Dibenedetto ${ }^{1}$, Antonella Angelini ${ }^{2}$, Antonella Colucci ${ }^{3}$, Luigi di Bitonto ${ }^{4}$, Carlo \\ Pastore $^{5}$, Brunella Maria Aresta ${ }^{6}$, Cinzia Giannini ${ }^{7}$ and Roberto Comparelli ${ }^{8}$ \\ 1,2,3 Department of Chemistry and CIRCC, University of Bari, Campus Universitario, Bari, Italy \\ ${ }^{4}$ METEA, VALBIOR - Project Apulia Region , Bari, Italy \\ 5,6,7,8 CNR-IC Istituto di Cristallografia, CNR, Bari, Italy
}

Correspondence should be addressed to: Angela Dibenedetto; angela.dibenedetto@uniba.it

Received date: 24 April 2014; Accepted date: 14 July 2014; Published date: 30 August 2016

Academic Editor: Riccardo Tesser

Copyright (c) 2016. Angela Dibenedetto, Antonella Angelini, Antonella Colucci, Luigi di Bitonto, Carlo Pastore, Brunella Maria Aresta, Cinzia Giannini and Roberto Comparelli. Distributed under Creative Commons CC-BY 4.0

\begin{abstract}
In this paper we describe our approach to solve the problem of the simultaneous transesterification of lipids (that requires a basic catalyst) and esterification of FFAs (that requires an acid catalyst) using mixed oxides ad hoc prepared. New mixed oxides based on calcium, cerium and aluminium have been used as catalysts in the reaction of trans-esterification of oils of different composition and quality, namely: i) extra virgin olive oil as a test case (low acidity) and ii) non-edible oil (high acidity), such as that extracted from aquatic biomass (Nannochloropsis $s p$

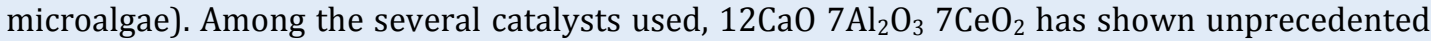
properties in terms of activity and resistance in the simultaneous transesterification/esterification.
\end{abstract}

Keywords: Nannochloropsis sp bio-oil, tunable catalyst, trans-esterification, fatty acids esterification.

Cite this Article as: Angela Dibenedetto , Antonella Angelini, Antonella Colucci, Luigi di Bitonto, Carlo Pastore, Brunella Maria Aresta, Cinzia Giannini and Roberto Comparelli (2016)," Tunable Mixed Oxides: Efficient Agents for the Simultaneous Trans-Esterification of Lipids and Esterification of Free Fatty Acids from Bio-Oils for the Effective Production of Fames" International Journal of Renewable Energy and Biofuels,

Vol. 2016 (2016), Article ID 204112, DOI: 10.5171/2016.204112 


\section{Introduction}

Biodiesel produced from renewable energy sources, such as vegetable oils (plants, microalgae) and animal fats has similar physical and chemical properties as the petroleum-derived-diesel. Among the biosources available for the biodiesel production, microalgae are of great interest since they grow much faster than terrestrial oilseed crops and produce higher oil yields per unit area (about 40 times more) (Singh and Dhar, 2011). In addition, they can produce both biofuels and valuable coproducts (omega 3, several metabolites of economic interest, astaxanthin, lutein, vitamin $\mathrm{E}$ and poly unsaturated fatty acids) (Scott et al., 2010). For such reason, they have a large potential for feed, food, cosmetics, and pharmaceutical industries. The biodiesel production from microalgae consists of two stages: the first one is the oil extraction that could be carried out using several techniques such as Soxhlet extraction (with n-hexane as solvent), the Bligh and Dyer method in which a chloroform methanol mixture is used as solvent, the microwave-oven technique, supercritical fluid extraction, ultrasounds-assisted extraction and pressurized fluid extraction. The second step is the catalytic transesterification of algal oil with methanol. Conventionally, the trans-esterification of vegetable oils occurs in presence of homogeneous basic catalysts, such as sodium or potassium hydroxides, carbonates or alkoxides (Sivasamy et al., 2009; Helwani et al., 2009; Demirbas AH and Demirbas I, 2007). The main advantages in by the use of homogeneous catalysts are their costeffectiveness and good performances. On the other hand, such application has some drawbacks, namely: i) the need to use a batch-process with a quite difficult or impossible catalyst recovery, ii) the conversion of FFAs into soaps that causes emulsification with glycerol and increases the separation costs. As a matter of fact, such technology generally requires refined oils as starting materials (the reagents have to be free of moisture and the FFAs content must not exceed 0.1-0.5 wt\%) (Knothe et al., 2005;
Sharma et al., 2008) and produces salt-rich watery glycerol and large volumes of wastewater. Conversely, in order to be competitive with conventional fossil-derived fuels, the feedstock for the production of biodiesel should be the cheapest possible, and the biodiesel production process should be based on the simplest manufacture technology (Demirbas 2008).

However, low quality oils from olive drupes, together with waste oils (fried oils from restaurants) or oils from non edible drupes and seeds, or else non-edible lipids extracted from seaweeds and microalgae, may be considered the correct source for "biodiesel" production. Such starting materials may contain an amount of FFAs as high as $20 \%$. Therefore, a direct base-catalysed transesterification of such lipid fraction significantly decreases the biodiesel yield because of the formation of soaps.

Feedstock containing large amounts of FFAs may require two different types of catalysts (acid and basic catalysts) that are usually employed in a two-stage process. An acid catalyst is first used for the esterification of FFAs that has to be removed before the base catalyst is added in the second stage for the trans-esterification of lipids. For having a most effective process, the esterification and trans-esterification should be combined in a consecutive-continuous cycle, (Demirbas 2009) which presents high costs.

A cost-effective solution for the conversion of feedstock with high FFAs content into FAMEs is the consecutive hydrolysis-esterification processes (hydroesterification). In this case, a single acid catalyst is used for the hydrolysis of lipids into glycerol and FFAs followed by the esterification of the latter catalyzed by the same acid catalyst. Typically, $\mathrm{Nb}_{2} \mathrm{O}_{5}$-based catalysts (Aranda et al., 2009) and strong acidic ion-exchange resins (Özbay et al., 2008) are used in such application.

A solid bifunctional catalyst with appropriate acid/basic properties able to simultaneously and effectively catalyze both the transesterification and esterification (one pot or

Angela Dibenedetto, Antonella Angelini, Antonella Colucci, Luigi di Bitonto, Carlo Pastore, Brunella Maria Aresta, Cinzia Giannini and Roberto Comparelli (2016), International Journal of Renewable Energy and Biofuels, DOI: 10.5171/2016.204112 
continuous-flow esterification of FFAs and trans-esterification of lipids) would represent an interesting and simple solution: very rare examples of such application are known (Jacobson et al., 2008; Bernhard Russbueldt et al., 2010). Such approach is the simplest in terms of plant design. Moreover, under heterogeneous catalysis conditions it is possible to associate the general advantage of an easy separation of the catalyst from the reaction products (in general the catalyst is separated by simple filtration affording a cleaner process) with its reuse. Such technology also avoids the formation of soaps and brings to a more selective production of FAMEs (purer product), and a more simple glycerol purification (99\% purity salt-free glycerol can be produced against $75 \%$ in the homogeneous process), avoiding wastes. In addition, heterogeneous catalysts are in general much more tolerant to water and FFAs present in the feedstock. Nevertheless, heterogeneous catalysts for FAMEs production generally require more severe working conditions than homogeneous catalysts: in particular, higher temperatures and pressures are requested. On the other hand, if supported catalysts are used, they tend to release the active species and the question opens whether the solid catalyst is active or the part in solution.

In this work we have prepared new mixed oxides based on ceria loaded with calcium oxide or alumina either separately or in combination, by using a dry-technique that avoids the use of water and the formation of large volumes of waste water. The different acid-base properties in function of the composition allow producing catalysts able to convert directly in one pot process low quality oil rich in FFAs into a product that responds to EU requisites for a use for the production of biodiesel. The choice of ceria as acidic support was suggested by our previous experience on its use in catalysis (Aresta et al., 2010; Dibenedetto at al., 2012). Calcium oxide was selected as the basic component as it is considered the most promising catalyst in trans-esterification, for its inexpensiveness, low solubility in methanol and absence of toxicity. Nevertheless, when
$\mathrm{CaO}$ alone is used (Sivasamy et al., 2009) an efficient trans-esterification is accompanied by micro-emulsions formation that makes complex the separation, increasing the cost of recovery of the final products. The production of $\mathrm{CaO}$ is generally carried out using $\mathrm{CaCO}_{3}$ or $\mathrm{Ca}\left(\mathrm{NO}_{3}\right)_{2}$ or $\mathrm{Ca}(\mathrm{OH})_{2}$ as precursors that are calcinated at a temperature in the range 800-1300 K. (Ettarh and Galwey, 1996). In this work, we introduce a new synthetic route (Aresta et al., 2013) in which the conversion of $\mathrm{CaCO}_{3}$ used as calcium oxide precursor is promoted by one of the co-reagent oxides, namely $\mathrm{CeO}_{2}$, making milder the conversion conditions so that, for example, the decarboxylation of $\mathrm{CaCO}_{3}$ to $\mathrm{CaO}$ quantitatively occurs at an unprecedented temperature of $823 \mathrm{~K}$, lowering the energy of production of the catalysts. $\mathrm{Al}_{2} \mathrm{O}_{3}$ was selected for its stabilization properties. As we have already shown (Aresta et al., 2010) in combination with $\mathrm{CeO}_{2}, \mathrm{Al}_{2} \mathrm{O}_{3}$ modulates the oxidative properties of the latter towards organics by interacting with the surface and making more difficult the surface oxygen-transfer. In this work, each oxide has been used alone to show its catalytic capacity towards the same substrate, and couples of oxides or quaternary oxides have been used. $\mathrm{CaO} \mathrm{Al}_{2} \mathrm{O}_{3}$ has also been used, that may not be considered a real mixed oxide. $\mathrm{CaO} \mathrm{CeO}_{2}$ and $\mathrm{CaO} \quad \mathrm{Al}_{2} \mathrm{O}_{3} \quad \mathrm{CeO}_{2}$ oxides with variable composition have been tested in order to demonstrate the effect of the acid and basic components on real mixtures of lipids and FFAs.

\section{Materials and Methods}

\section{Materials}

For this study a dense culture of Nannochloropsis sp was used and purchased from Reefsnow, Milan-IT. Nannochloropsis $\mathrm{sp}$ is a small green microalgae that is extensively used in the aquaculture industry for growing small zooplankton such as rotifers. All reagents and solvents were commercial products.

The analysis of the extracted bio-oil and of

Angela Dibenedetto, Antonella Angelini, Antonella Colucci, Luigi di Bitonto, Carlo Pastore, Brunella Maria Aresta, Cinzia Giannini and Roberto Comparelli (2016), International Journal of Renewable Energy and Biofuels, DOI: 10.5171/2016.204112 
FAMEs was carried out using a FOCUS Gas Chromatograph (capillary column: $30 \mathrm{~m}$; VARIAN GC Select biodiesel for FAME; $\emptyset 0.32$ $\mathrm{mm}, 0.25 \mu \mathrm{m}$ film) with a FID detector. Helium was used as the carrier gas. The oven temperature was set at $423 \mathrm{~K}$ : it was initially held for $13 \mathrm{~min}$ at such temperature that was then increased to $483 \mathrm{~K}$ for $13 \mathrm{~min}$ and to $503 \mathrm{~K}$ for $15 \mathrm{~min}$ (at a rate of $5 \mathrm{~K} / \mathrm{min}$ ). Injector and detector temperature were set at $503 \mathrm{~K}$ and $523 \mathrm{~K}$, respectively.

The quantification of mono-, di-, and triglycerides was done by using a Gas Chromatograph TRACE Ultra (True cold Oncolumn, Thermo Scientific TRACE TRBIODIESEL (G) $10 \mathrm{~m}, \varnothing 0.32 \mathrm{~mm}, 0.1 \mu \mathrm{m}$ film). The temperature of the detector was set at $653 \mathrm{~K}$. GC-MS analyses for the identification of mono methyl esters were carried out with a gas chromatograph Shimadzu 17 A (capillary column: $30 \mathrm{~m}$; MDN-5S; Ø $0.25 \mathrm{~mm}, 0.25 \mu \mathrm{m}$ film) coupled to a Shimadzu QP5050 A mass spectrometer.

Quantitative determinations on the reaction solutions were performed using a Hewlett
Packard 6850 GC-FID (capillary column: 30 m; Carbowax; Ø 0.25 mm, $0.25 \mu \mathrm{m}$ film).

For the Ultrasound-assisted extraction, the ultrasound device "Starsonic 60 (frequency $28.34 \mathrm{kHz}$ )" was used while Microwave assisted extraction was carried out using a professional microwave oven "Milestone start E”.

A stainless steel autoclave equipped with a pressure gauge connected to an electronic device for the control of the temperature was used for thermochemical liquefaction.

The High Energy Milling (HEM) apparatus Polviresette 7 was from FRITSCH.

\section{Characterization of Nannochloropsis sp Microalgae}

Nannochloropsis sp dried at $298 \mathrm{~K}$ was characterized for its dry matter content (CEN/TS 14774 method), ash residue (CEN TS/14775 method), High Heat Value (CEN/TS 14918 method) and by elemental analysis as reported below. The results are summarised in Table 1.

Table 1: Characterization of Nannochloropsis sp Microalgae

\begin{tabular}{|c|c|c|c|c|c|c|}
\hline Dry matter (\%) & Ash (\%) & C (\%) & H (\%) & N (\%) & S (\%) & HHV (MJ/kg) \\
\hline 80 & 12.32 & 41 & 5.7 & 5.9 & 0.08 & 17.52 \\
\hline
\end{tabular}

\section{Dry Matter}

The content in dry-matter was determined according to the CEN/TS 14774 methodology (2010) (Table 1). $1 \mathrm{~g}$ (powdered) of wet biomass was dehydrated in a oven at $376 \mathrm{~K}$ for $12 \mathrm{~h}$.

\section{Ash and Mineral Content}

This was determined according to the CEN TS/14775 methodology (2010) (Table 1). In order to remove carbon, about $1 \mathrm{~g}$ of powered dry biomass, in a porcelain container, was ignited and incinerated in a muffle furnace at about $823 \mathrm{~K}$ for $8 \mathrm{~h}$. The total ash was expressed as percentage of dry weight.

\section{High Heat Value}

HHV was calculated according to the CEN/TS 14918 methodology (2010), measuring the C, $\mathrm{H}, \mathrm{N}, \mathrm{S}$ content of the biomass (Table 1). A direct measurement by using a combustion apparatus demonstrated that the calculated value had a $5 \%$ uncertainty.

\section{Techniques for lipid extraction}

Lipids from dry and ground biomass were extracted using different techniques. In 
particular, the Soxhlet extraction, ultrasounds assisted extraction, microwave extraction and thermo-chemical liquefaction were carried out as described below:

\section{Soxhlet-extraction}

The extraction was performed starting from $5 \mathrm{~g}$ of dried biomass. Liquid nitrogen was used to break the cellular membrane in order to increase the extraction yield. The extraction was carried out for $6 \mathrm{~h}$ using 50 $\mathrm{mL}$ of solvent: either chloroform-methanol $(1: 2 \mathrm{v} / \mathrm{v})$ or $\mathrm{n}$-hexane were used according to the different processing of the algae or biooil.

\section{Ultrasound-assisted (US) Extraction}

A mixture of dried biomass (1.5 g) and $33 \mathrm{~mL}$ of solvent [chloroform-methanol $(1: 2 \mathrm{v} / \mathrm{v})$ or $\mathrm{n}$-hexane] was sonicated for $1 \mathrm{~h}$ in an ultrasounds apparatus at 293, 323 and $343 \mathrm{~K}$.

\section{Microwave-assisted (MW) Extraction}

A mixture of dried biomass $(1 \mathrm{~g})$ and $33 \mathrm{~mL}$ of solvent [chloroform-methanol (1:2 v/v), or $\mathrm{n}$-hexane] was irradiated by microwave $(1200 \mathrm{~W})$ at $373 \mathrm{~K}$ for $20 \mathrm{~min}$.

\section{Characterisation of the Lipidic Fraction}

\section{Thermo-chemical Liquefaction}

$20 \mathrm{~g}$ of fresh biomass was heated in a stainless steel autoclave for $1 \mathrm{~h}$ at $523 \mathrm{~K}$ under N2 (3.0 MPa). After such time, the autoclave was cooled to room temperature and depressurized. The autoclave was then opened and the reaction mixture recovered and treated with $\mathrm{CH} 2 \mathrm{Cl} 2(3 \times 5 \mathrm{~mL})$ in order to extract the bio-oil. In each step the organic solution was separated from the aqueous/solid suspension. The organic fractions were collected and the solvent evaporated. The bio-oil was weighted and further treated to produce FAMEs.

At the end of each extraction the bio-oil phase was separated from the residual solid biomass by filtration. The residual biomass was washed with the same solvent used for the extractions. The solvent of the extracted portion was removed in a rotary evaporator at $333 \mathrm{~K}$ and any remaining traces were removed by placing the flask with the extract in an oven at $353 \mathrm{~K}$ for a preset interval, followed by cooling in a dessicator and weighing, such procedure was then repeated until the difference between two consecutive weights was smaller than $2 \mathrm{mg}$. In such a way, the extraction yield of lipids relative to the dry biomass was evaluated.

Table 2: FFAs composition (expressed as methyl esters) of the algal lipid fraction

\begin{tabular}{|c|c|}
\hline Fatty acid & \% Composition \\
\hline Lauric acid & 0.3 \\
\hline Myristic acid & 4.6 \\
\hline Palmitic acid & 25.4 \\
\hline Palmitoleic acid & 32.2 \\
\hline Stearic acid & 0.5 \\
\hline Oleic acid & 5.4 \\
\hline Linoleic acid & 2.9 \\
\hline Linolenic acid & 1.9 \\
\hline Arachidonic acid & 2.5 \\
\hline EPA, Eicosapentenoic acid & 24.3 \\
\hline
\end{tabular}

Angela Dibenedetto, Antonella Angelini, Antonella Colucci, Luigi di Bitonto, Carlo Pastore, Brunella Maria Aresta, Cinzia Giannini and Roberto Comparelli (2016), International Journal of Renewable Energy and Biofuels, DOI: 10.5171/2016.204112 
The Fatty Acid composition (\% expressed as methyl esters) in the extracted algal lipid fraction was determined as shown in Table 2. (AOCS Ce 2-66). The mono- di- triglycerides composition in the extracted algal lipid fraction was analyzed using GC in according to EN 14105 method (2011).

\section{Synthesis of the Catalysts}

$\mathrm{Ce}\left(\mathrm{NO}_{3}\right)_{3} \cdot 6 \mathrm{H}_{2} \mathrm{O}, \quad \mathrm{Al}_{2} \mathrm{O}_{3}$ and $\mathrm{CaCO}_{3}$ were commercial products purchased from Aldrich. Pure $\mathrm{CeO}_{2}$ and $\mathrm{CaO}$ were obtained by treating respectively $\mathrm{Ce}\left(\mathrm{NO}_{3}\right)_{3} \cdot 6 \mathrm{H}_{2} \mathrm{O}$ and $\mathrm{CaCO}_{3}$ at $823 \mathrm{~K}$ or $1373 \mathrm{~K}$.

All the mixed oxides were synthesized using a solid state technique (Aresta et al., 2013); the required amount of precursors were mixed together in the solid state using a High Energy Milling apparatus (HEM) equipped with spheres and basket made of agata. At the end of the milling ( $1 \mathrm{~h}$ at $700 \mathrm{rpm})$ the mixtures were calcined for $3 \mathrm{~h}$ at $823 \mathrm{~K}$ or $1373 \mathrm{~K}$.

All the synthesized mixed oxides were characterized through elemental analysis, BET, TPD and XPS. (See S.I)

\section{Synthesis of xCaO $\mathrm{CeO}_{2}$ Mixed Oxides}

$\mathrm{xCaO} \mathrm{CeO}_{2}$ mixed oxides (molar ratio $\mathrm{x}$ equal to $0.1,0.5,1$ ) were synthesized starting from cerium nitrate hexahydrate and calcium carbonate purchased by Aldrich. In particular, $4.201 \mathrm{~g}$ of $\mathrm{Ce}\left(\mathrm{NO}_{3}\right)_{3} \cdot 6 \mathrm{H}_{2} \mathrm{O}$ were mixed together with $0.097 \mathrm{~g}, 0.484 \mathrm{~g}$ and $0.968 \mathrm{~g}$ of $\mathrm{CaCO}_{3}$; respectively using the $\mathrm{HEM}$ apparatus. The obtained mixtures were then calcined at $823 \mathrm{~K}$ or $1373 \mathrm{~K}$ as required.

\section{Synthesis of $\mathrm{CeO}_{2} \mathrm{Al}_{2} \mathrm{O}_{3}$ Mixed Oxides}

$2.376 \mathrm{~g}$ of $\mathrm{Ce}\left(\mathrm{NO}_{3}\right)_{3} \cdot 6 \mathrm{H}_{2} \mathrm{O}$ and $0.558 \mathrm{~g}$ of $\mathrm{Al}_{2} \mathrm{O}_{3}$ were mixed together in the solid state using the HEM apparatus. The mixture was then calcined at $823 \mathrm{~K}$ or $1373 \mathrm{~K}$ to obtain the desired oxides.

\section{Synthesis of $\mathrm{CaO}_{2} \mathrm{Ol}_{3}$ Spinel-like oxides}

$0.950 \mathrm{~g}$ of $\mathrm{CaCO}_{3}$ were mixed with $0.9658 \mathrm{~g}$ of $\mathrm{Al}_{2} \mathrm{O}_{3}$ in the HEM apparatus. The mixture was then calcined at $823 \mathrm{~K}$ or $1373 \mathrm{~K}$.

\section{Synthesis of $12 \mathrm{CaO} 7 \mathrm{Al}_{2} \mathrm{O}_{3}$ mixed oxides}

$12 \mathrm{CaO} 7 \mathrm{Al}_{2} \mathrm{O}_{3}$ was synthesized as reported in the literature (Matsuishi et al., 2004)

\section{Synthesis of $12 \mathrm{CaO} \quad \mathrm{7Al}_{2} \mathrm{O}_{3} \quad \mathrm{xCeO}_{2}$ Mixed oxides}

$12 \mathrm{CaO} \quad 7 \mathrm{Al}_{2} \mathrm{O}_{3} \quad \mathrm{xCeO}_{2}$ mixed oxides (molar ratio $\mathrm{x}$ equal to $3,7,12$ ) were synthesized starting from $\mathrm{CaCO}_{3}, \mathrm{Al}_{2} \mathrm{O}_{3}$ and $\mathrm{Ce}\left(\mathrm{NO}_{3}\right)_{3} \cdot 6 \mathrm{H}_{2} \mathrm{O}$. In particular, $0.931 \mathrm{~g}$ of $\mathrm{CaCO}_{3}$ and $0.553 \mathrm{~g}$ of $\mathrm{Al}_{2} \mathrm{O}_{3}$ were mixed together to $1.009 \mathrm{~g}, 2.356 \mathrm{~g}$ and $4.039 \mathrm{~g}$ of $\mathrm{Ce}\left(\mathrm{NO}_{3}\right)_{3} \cdot 6 \mathrm{H}_{2} \mathrm{O}$ using the HEM apparatus. The mixtures were then calcined for $3 \mathrm{~h}$ at $823 \mathrm{~K}$ or $1373 \mathrm{~K}$, to obtain the final oxides (Aresta et al., 2013).

\section{Trans-esterification tests}

$1.8 \mathrm{~g}$ of extracted oil was placed in a steel autoclave and reacted with $5 \mathrm{~mL}$ of methanol (molar ratio methanol:oil 50:1) at $453 \mathrm{~K}$ and $5.0 \mathrm{MPa}$ of nitrogen for $3 \mathrm{~h}$. In each test 50 mg of catalyst were used. At the end of the reaction, the autoclave was cooled using an ice bath and the reaction mixture was transferred into centrifuge tubes which were centrifuged for the separation of the catalyst. The isolation of the organic phase was made by evaporation of methanol under vacuum. Over $99 \%$ of the original biomass was recovered. Such organic phase was quickly washed with distilled water (1 $\mathrm{mL} \times 3)$ to remove the residual glycerol produced by the reaction of trans-esterification and then it was dried under vacuum. Water did not contain FFAs nor lipids at a level above trace amount. Finally, the organic phase was analyzed by GC and GC-MS. 


\section{Fatty Acid Composition of Extracted Oil and FAMEs Analysis}

The AOCS method Ce 2-66 (1997) was used for the preparation of FAME; $0.1 \mathrm{~g}$ of sample was placed into a test tube, and $1 \mathrm{~mL}$ of heptane and $0.050 \mathrm{~g}$ of methyl heptadecanoate (internal standard) were added. To convert all fatty acid components of bio-oil into the mono-methyl esters to the solution, $1 \mathrm{~mL}$ of $\mathrm{KOH}-\mathrm{CH}_{3} \mathrm{OH}$ was added and shaken vigorously with a vortex for $1 \mathrm{~min}$; a biphasic system was formed. $1 \mu \mathrm{l}$ of the organic phase was injected into FOCUS-GC for the analysis.

The quantification of FAMEs was performed according to the regulations (CE) $n$. $796 / 2002$ (2002). $50 \mathrm{mg}$ of sample was placed into test tubes, and $4 \mathrm{~mL}$ of heptane was added, $0.050 \mathrm{~g}$ of methyl heptadecanoate was used as internal standard. $1 \mu \mathrm{L}$ of such solution was injected to FOCUS-GC for analysis.

\section{Discussion}

\section{Effect of the Solvent Used for Bio-Oil Extraction}

The lipid fraction in microalgae is mainly formed by triglycerides (15-25\%), phospholipids and glycolipids (60-75\%), sterols (5-10\%) and FFAs (5-18\%). Triglycerides are non-polar molecules and so are soluble in low-polar solvent such as nhexane or diethyl ether. On the other hand, phospholipids and glycolipids are polar molecules, and so polar solvents such as methanol or chloroform or ethanol are required for their extraction. In Table 3 are reported the bio-oil yields obtained using different techniques and different solvents.

Lipids were extracted from microalgae using either chloroform-methanol (C:M) or nhexane $(\mathrm{H})$. Comparing the yield of extraction (Table 3), it is possible to observe that the binary mixture C:M gives higher yields of extracted bio-oil with respect to n-hexane with all the used techniques. Most likely, this is due to the low polarity of n-hexane that allows the selective extraction of triglycerides leaving back the other components of the lipid fraction. (D. Ríos et al., 2013), If on one hand, the use of n-hexane as extraction solvent is advantageous from an environmental point of view, the lower extraction yields make more negative the economics of the process. The use of moderate amounts of CM may be a more convenient solution if the solvent is recovered and recycled

Among the used techniques; MW showed the best results in the shorter time of extraction ( $20 \mathrm{~h}$ vs $60 \mathrm{~h}$ for all the other methods).

Thermo-chemical liquefaction allowed to obtain an interesting bio-oil yield (68\%). However, it is worth to underline that the final oil contains a lot of contaminants such as carbohydrates, proteins and pigments that need to be removed before the catalytic conversion of bio-oil into bio-diesel.

\section{Catalytic Activity of the Mixed-Oxides in the Conversion of Lipids and FFAs into FAMEs}

As mentioned above, only rare examples are available in the literature of utilization of bifunctional heterogeneous catalysts for the simultaneous conversion of FFAs and glycerides (MG, DG, TG) into the relevant methyl esters. This approach drastically simplifies the trans-esterification technology, because both the preliminary refining of the oil is avoided and the processing of the final reaction mixture is reduced to a simple filtration for catalyst recovery. Obviously, a very robust and active catalytic system is needed as FFAs may easily attach and dissolve the catalyst under the reaction conditions; this occurs for example with $\mathrm{CaO}$. In the present paper the activity of the newly synthesised mixed and single oxides and their recyclability was tested in the conversion of oil extracted from microalgae rich in FFAs. The correlation composition of the catalyst-activity is also described. 
Table 3: Amount of bio-oil obtained under different conditions from Nannochloropsis sp

\begin{tabular}{|c|c|c|c|c|c|}
\hline \multirow{2}{*}{$\begin{array}{l}\text { Extraction } \\
\text { Method }\end{array}$} & \multirow{2}{*}{$\begin{array}{c}\text { Biomass dry } \\
\text { weight (g) } \\
\text { (g) }\end{array}$} & \multicolumn{2}{|c|}{ Working Condition } & \multirow{2}{*}{$\begin{array}{l}\text { Lipid extraction } \\
\text { solvent }(\mathrm{mL})\end{array}$} & \multirow{2}{*}{$\begin{array}{c}\text { Yield bio-oil } \\
\text { (\%) }\end{array}$} \\
\hline & & $\mathbf{T}(\mathrm{K})$ & $\begin{array}{l}\text { time } \\
(\mathrm{min})\end{array}$ & & \\
\hline \multirow{2}{*}{ Soxhlet } & \multirow{2}{*}{5} & \multirow{2}{*}{$>343$} & \multirow{2}{*}{360} & $\begin{array}{c}\text { n-hexane } \\
(50)\end{array}$ & 9 \\
\hline & & & & $\begin{array}{c}\mathrm{CHCl}_{3}: \mathrm{CH}_{3} \mathrm{OH} 1: 2 \\
(50)\end{array}$ & 40 \\
\hline \multirow{6}{*}{ US assisted } & & 293 & \multirow{3}{*}{60} & \multirow{3}{*}{$\begin{array}{c}\text { n-hexane } \\
\text { (33) }\end{array}$} & 3.3 \\
\hline & 1.5 & 323 & & & 3.6 \\
\hline & & 343 & & & 4.0 \\
\hline & & 293 & \multirow{3}{*}{60} & \multirow{3}{*}{$\begin{array}{c}\mathrm{CHCl}_{3}: \mathrm{CH}_{3} \mathrm{OH} 1: 2 \\
(50)\end{array}$} & 40 \\
\hline & 1.5 & 323 & & & 38 \\
\hline & & 343 & & & 39 \\
\hline \multirow{2}{*}{ MW assisted } & \multirow[b]{2}{*}{1} & \multirow{2}{*}{363} & \multirow{2}{*}{20} & \multirow{2}{*}{$\begin{array}{c}\text { n-Hexane } \\
\mathrm{CHCl}_{3}: \mathrm{CH}_{3} \mathrm{OH} 1: 2\end{array}$} & 11 \\
\hline & & & & & 41 \\
\hline $\begin{array}{c}\text { Thermo-chemical } \\
\text { liquefaction }\end{array}$ & 20 & 523 & 60 & $\begin{array}{c}\mathrm{CH}_{2} \mathrm{Cl}_{2} \\
(15)\end{array}$ & 68 \\
\hline
\end{tabular}

A control test was made using "extra virgin olive-oil" (Table 4) characterized by a low concentration of FFAs, waxes, free sterols and aliphatic alcohols, species that can poison the catalysts under the reaction conditions by modifying their surface and deactivating them very rapidly. Such test was useful for understanding the role that contaminants of a real matrix may have on the catalysts.

Moreover, the influence of the temperature of calcination namely 823 and $1373 \mathrm{~K}$ was investigated. From the collected data it is clear that already calcining at $823 \mathrm{~K}$ for $3 \mathrm{~h}$ the starting mixture of powders, it is possible to obtain catalysts that are very active in the trans-esterification of extra virgin olive oil.

As already reported, (Zabeti et al., 2009) calcium oxide is a very active system in the trans-esterification process. We found that calcium carbonate calcined at $1373 \mathrm{~K}$ (Entry 8 , Table 4) is much more active than that calcined at $823 \mathrm{~K}$ (Entry 1) that may contain a larger amount of unreacted $\mathrm{CaCO}_{3}$.

The drawback is that pure calcium oxide emulsify in the operative conditions, making very difficult the separation of the catalyst from the reaction mixture and the recovery of the final product. For this reason we have prepared mixed oxides of calcium oxide with ceria or alumina. Actually, the samples of ternary oxides obtained upon calcination at $823 \mathrm{~K}$ seem to be more active than those calcined at $1373 \mathrm{~K}$, (Table 4, Entries 5-6-7 vs 12-13-14) probably because of the negative effect of the reduction of the surface upon calcination at higher temperature (Ferrer et al., 2010). 
Table 4: Trans-esterification of extra-virgin olive oil using several mixed oxides. Bold characters highlight FAMEs responding to EU regulations. $\mathrm{MG}=\mathrm{Mono}-\mathrm{DD}=\mathrm{Di}-$ TG=Triglycerides

\begin{tabular}{|c|c|c|c|c|c|c|}
\hline \multirow{2}{*}{ Entry } & \multirow{2}{*}{ Catalysts } & \multicolumn{4}{|c|}{$\%$ Composition of the organic phase } & \multirow{2}{*}{ Sap. matter } \\
\hline & & FAMEs & MG & DG & TG & \\
\hline \multicolumn{7}{|c|}{ Calcined at $823 \mathrm{~K}$} \\
\hline 1 & $\mathrm{CaO}$ from $\mathrm{CaCO}_{3}$ & 7.6 & 1.55 & 8.20 & 72.37 & 89.72 \\
\hline 2 & $\mathrm{Al}_{2} \mathrm{O}_{3}$ & 15.1 & 3.69 & 8.66 & 62.93 & 90.38 \\
\hline 3 & $\mathrm{CeO}_{2}$ & 11.1 & 0.90 & 6.00 & 75.63 & 93.63 \\
\hline 4 & $\mathrm{CaO} \mathrm{CeO}_{2}$ & 97.0 & 0.79 & 0.07 & 0.11 & 97.97 \\
\hline 5 & $12 \mathrm{CaO} 7 \mathrm{Al}_{2} \mathrm{O}_{3} 3 \mathrm{CeO}_{2}$ & 96.8 & 0.80 & 0.02 & 0.05 & 97.67 \\
\hline 6 & $12 \mathrm{CaO} 7 \mathrm{Al}_{2} \mathrm{O}_{3} 7 \mathrm{CeO}_{2}$ & 96.7 & 0.65 & 0.01 & 0.01 & 97.37 \\
\hline 7 & $12 \mathrm{CaO} 7 \mathrm{Al}_{2} \mathrm{O}_{3} 1_{2} \mathrm{CeO}_{2}$ & 97.1 & 0.80 & 0.01 & 0.01 & 97.92 \\
\hline \multicolumn{7}{|c|}{ Calcined at $1373 \mathrm{~K}$} \\
\hline 8 & $\mathrm{CaO}_{\text {from } \mathrm{CaCO}_{3}}$ & 97.5 & 0.91 & 0.01 & 0.01 & 98.43 \\
\hline 9 & $\mathrm{Al}_{2} \mathrm{O}_{3}$ & 10.2 & 2.25 & 8.58 & 68.74 & 89.77 \\
\hline 10 & $\mathrm{CeO}_{2}$ & 3.1 & 0.35 & 4.69 & 83.01 & 91.15 \\
\hline 11 & $\mathrm{CaO} \mathrm{CeO}{ }_{2}$ & 96.5 & 0.79 & 0.01 & 0.09 & 97.39 \\
\hline 12 & $12 \mathrm{CaO} 7 \mathrm{Al}_{2} \mathrm{O}_{3} 3 \mathrm{CeO}_{2}$ & 34.1 & 9.78 & 12.1 & 34.16 & 90.18 \\
\hline 13 & $12 \mathrm{CaO} 7 \mathrm{Al}_{2} \mathrm{O}_{3} 7 \mathrm{CeO}_{2}$ & 92.0 & 1.07 & 0.01 & 0.02 & 93.10 \\
\hline 14 & $12 \mathrm{CaO} 7 \mathrm{Al}_{2} \mathrm{O}_{3} 12 \mathrm{CeO}_{2}$ & 64.0 & 8.45 & 4.85 & 8.33 & 85.63 \\
\hline
\end{tabular}

In Table 5, we report the experimental results of the direct conversion of bio-oil (with a $17.8 \%$ FFAs content) extracted from microalgae Nannochloropsis using hexane as extraction solvent into FAMEs; it is of interest to compare the activity of ternary, binary and single metal oxide systems.

All catalysts were compared in the same operative conditions for what concerns: i) oil:methanol ratio, ii) $\mathrm{w} / \mathrm{w}$ oil:catalyst, iii) temperature; iv) time of reaction; v) $\mathrm{N}_{2}$ pressure. Ceria alone (Entry 4) has good catalytic properties for the direct esterification of FFAs into the methyl-esters; the residual FFA is only $0.32 \%$ with respect to $17.8 \%$ of the extracted bio oil. Conversely, the residual amount of TG-DG-MG is quite high. Pure calcium oxide obtained from
$\mathrm{CaCO}_{3} \quad$ (Entry 2) efficiently converts glycerides into methyl-esters, but it affords a system very difficult to handle because of micro-dispersion of calcium salts while leaves almost unaffected the FFAs. Mixed oxides composed by calcium and ceria (Entries 5, 6, 7) show an activity in transesterification and in the direct esterification of FFAs depending on the composition of the ternary system; $\mathrm{CaO}^{-} \mathrm{CeO}_{2}$ is the most efficient.

The catalytic systems constituted from Al-Ce (Entry 8) and Ca-Al (Entries 9-10) do not convert efficiently the starting oil into FAMEs at the same level as $\mathrm{Ca}-\mathrm{Ce}$, confirming the poor activity of $\mathrm{Al}_{2} \mathrm{O}_{3}$ and the acidic properties of $\mathrm{CeO}_{2}$. 
Table 5: Reactivity of various mixed oxides in the trans-esterification of bio oil

\begin{tabular}{|c|c|c|c|c|c|c|c|}
\hline \multirow{2}{*}{ Entry } & \multirow{2}{*}{ Catalysts } & \multicolumn{5}{|c|}{$\%$ Composition of the organic phase } & \multirow{2}{*}{ Sap. Matter } \\
\hline & & FAMEs & MG & DG & TG & FFA & \\
\hline 1 & $\begin{array}{c}\mathrm{CaCO}_{3} \text { calcined at } 823 \\
\mathrm{~K}\end{array}$ & 17.92 & 3.85 & 13.52 & 47.17 & 14.57 & 97.0 \\
\hline 2 & $\begin{array}{c}\mathrm{CaCO}_{3} \text { calcined at } \\
1373 \mathrm{~K}^{*}\end{array}$ & 73.80 & 3.85 & 2.22 & 0.54 & 17.00 & 97.4 \\
\hline 3 & $\mathrm{Al}_{2} \mathrm{O}_{3}$ & 13.22 & 2.61 & 11.96 & 54.88 & 15.70 & 98.4 \\
\hline 4 & $\mathrm{CeO}_{2}$ & 26.49 & 0.55 & 7.67 & 63.23 & 0.32 & 98.3 \\
\hline 5 & $0.1 \mathrm{CaO} \mathrm{CeO}_{2}$ & 33.15 & 3.59 & 11.76 & 46.36 & 0.78 & 95.6 \\
\hline 6 & $0.5 \mathrm{CaO} \mathrm{CeO}{ }_{2}$ & 47.78 & 3.61 & 10.21 & 34.80 & 0.80 & 97.2 \\
\hline 7 & $\mathrm{CaO} \mathrm{CeO}_{2}$ & 95.62 & 0.91 & 0.02 & 0 & 0.68 & 97.2 \\
\hline 8 & $\mathrm{Al}_{2} \mathrm{O}_{3} \mathrm{CeO}_{2}$ & 32.25 & 2.51 & 13.12 & 49.4 & 0.82 & 98.1 \\
\hline 9 & $\mathrm{CaO} \mathrm{Al} \mathrm{O}_{3}$ & 28.57 & 5.85 & 13.98 & 35.97 & 13.45 & 97.8 \\
\hline 10 & $12 \mathrm{CaO} 7 \mathrm{Al}_{2} \mathrm{O}_{3}$ & 33.76 & 7.16 & 11.02 & 26.80 & 17.5 & 96.2 \\
\hline 11 & $12 \mathrm{CaO} 7 \mathrm{Al}_{2} \mathrm{O}_{3} 3 \mathrm{CeO}_{2}$ & 90.08 & 0.85 & 0.02 & 0.02 & 5.40 & 97.1 \\
\hline 12 & $12 \mathrm{CaO} 7 \mathrm{Al}_{2} \mathrm{O}_{3} 7 \mathrm{CeO}_{2}$ & 95.50 & 0.88 & 0.01 & 0.01 & 0.70 & 97.1 \\
\hline 13 & $12 \mathrm{CaO} 7 \mathrm{Al}_{2} \mathrm{O}_{3} 12 \mathrm{CeO}_{2}$ & 96.1 & 0.5 & 0.01 & 0.02 & 0.50 & 97.2 \\
\hline
\end{tabular}

We have investigated the properties of the calcium-cerium compounds by studying in detail the correlation of the activity to the composition of the calcium/cerium mixture. (Fig. 1)

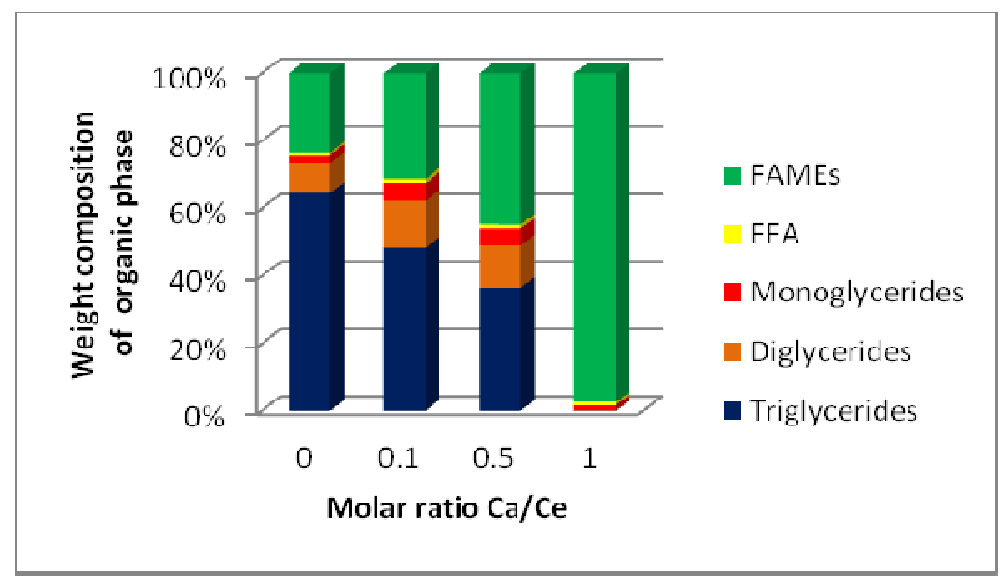

Figure 1: Effect of the different molar ratio $\mathrm{Ca} / \mathrm{Ce}$ in the trans-esterification of bio oil for the production of FAMEs 
As already mentioned, the cerium oxide shows a low activity in the transesterification process, but it catalyzes very efficiently the FFAs esterification with methanol. Increasing the amount of calcium in the binary oxide from 0 to $1: 1$ molar ratio with Ce, it is possible to observe an increase of the activity in the trans-esterification of glycerides. When the molar ratio calcium/cerium is increased to the unitary value, it is possible to convert the entire starting bio-oil into FAMEs (Fig. 1).

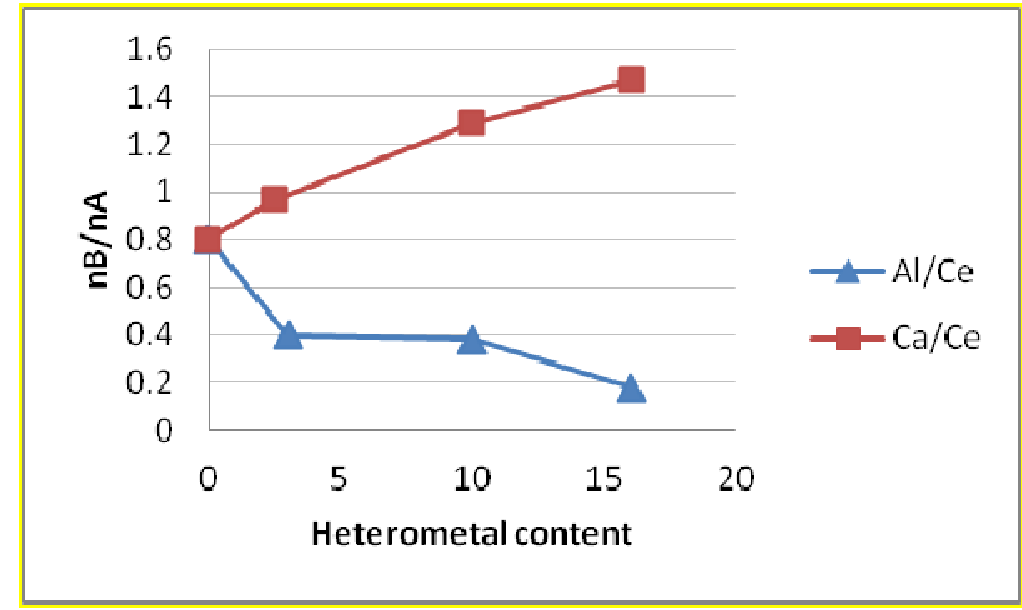

Figure 2: Dependence of the $n_{B} / n_{A}$ (strong sites) on the concentration of the heterometal (Ca or $\mathrm{Al}$ ) into the $\mathrm{CeO}_{2}$ matrix

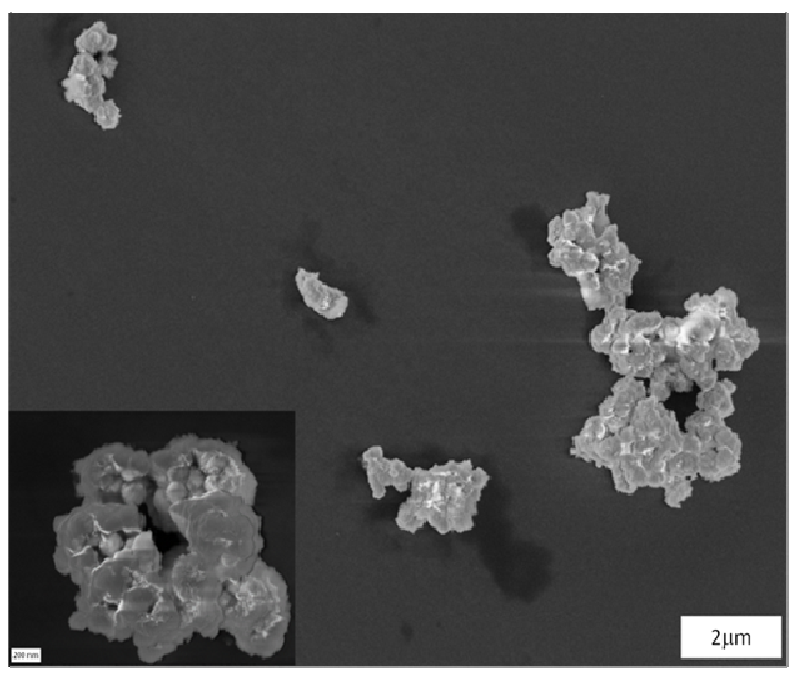

Figure S1

Angela Dibenedetto, Antonella Angelini, Antonella Colucci, Luigi di Bitonto, Carlo Pastore, Brunella Maria Aresta, Cinzia Giannini and Roberto Comparelli (2016), International Journal of Renewable Energy and Biofuels, DOI: 10.5171/2016.204112 


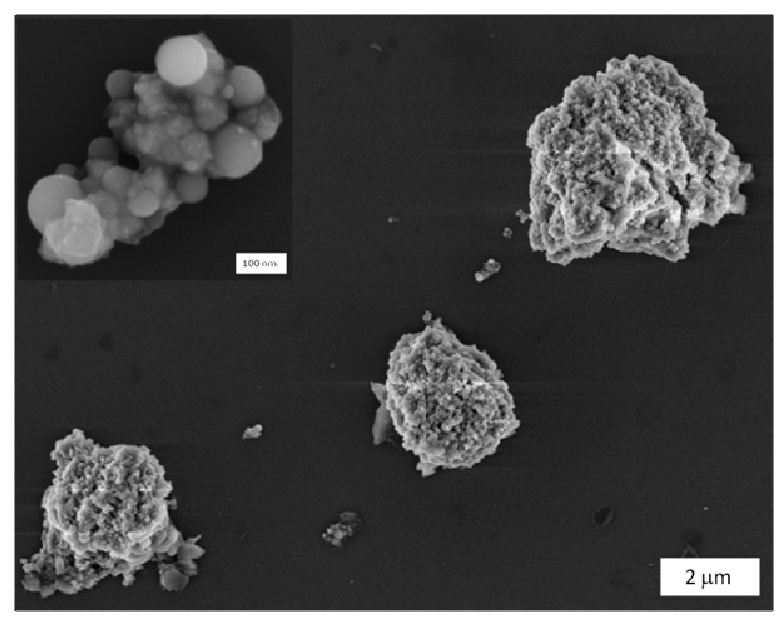

Figure S2

Such improvement of activity, strictly connected with the calcium content, may be justified by the increase of the number of strong basic and acid sites determined with TPD experiments (Fig 2).
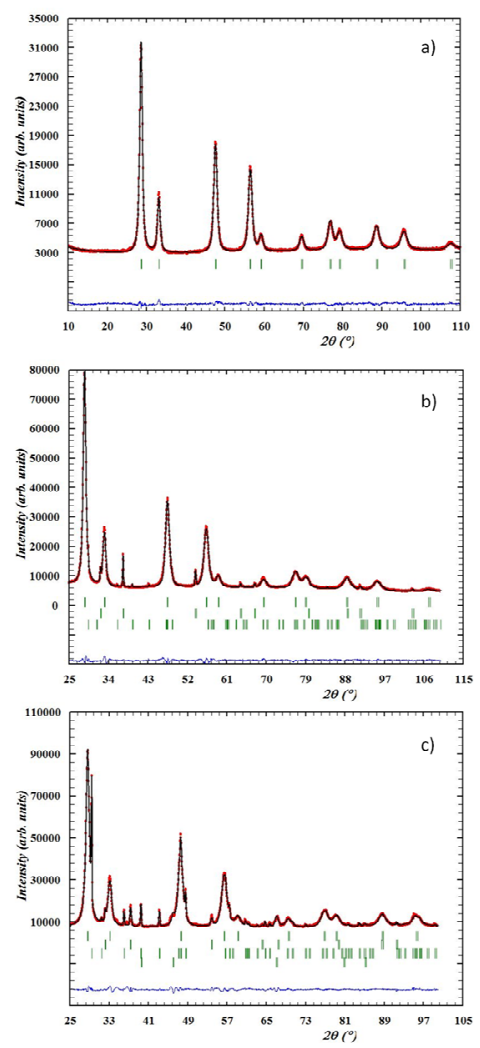

Figure S3

Angela Dibenedetto, Antonella Angelini, Antonella Colucci, Luigi di Bitonto, Carlo Pastore, Brunella Maria Aresta, Cinzia Giannini and Roberto Comparelli (2016), International Journal of Renewable Energy and Biofuels, DOI: 10.5171/2016.204112 


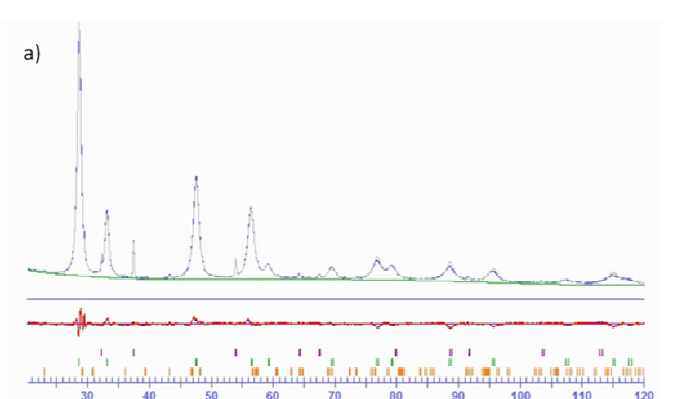

b)

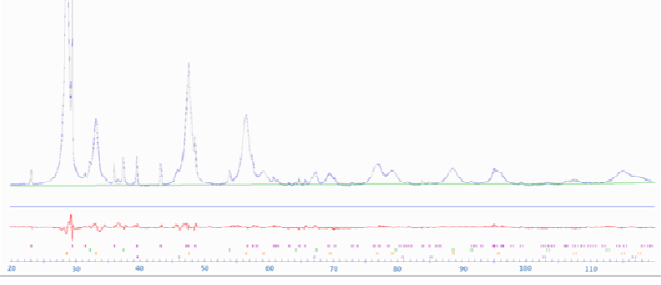

Figure S4
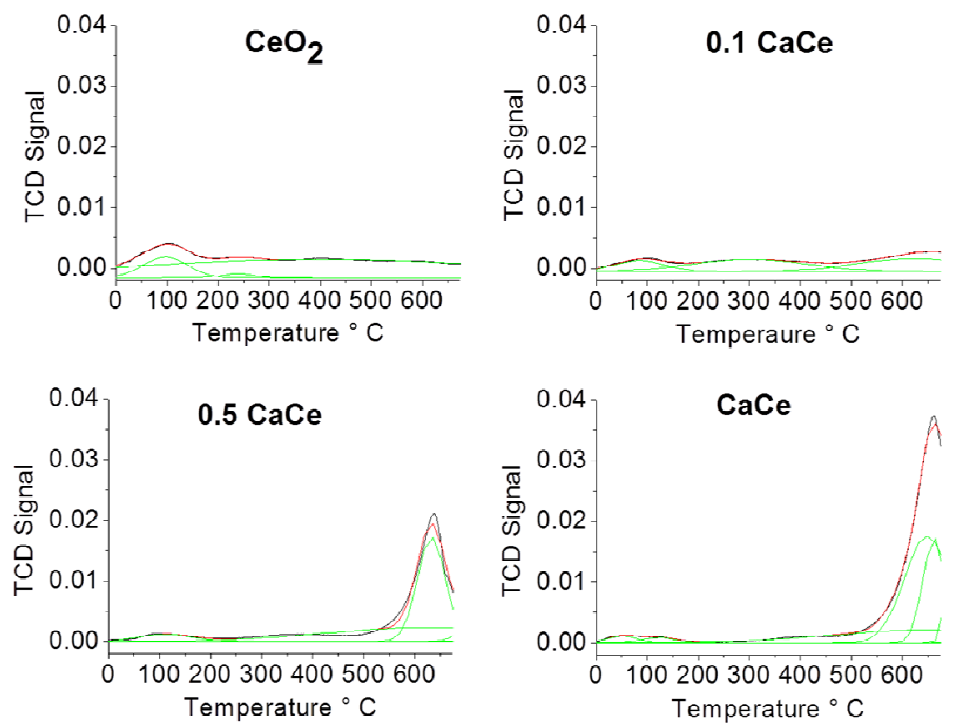

Figure S5

Figure 2 shows that the ratio $\mathrm{n}_{\mathrm{B}} / \mathrm{n}_{\mathrm{A}}$ (basic sites/acid sites) depends on the composition of the oxides. Strong sites ( $7>500 \mathrm{~K}$ ) are considered. The number of sits can be calculated; data can be found in the Supporting Information (Table S4)
The effect of the weight ratio catalyst/oil on the FAMEs synthesis was also investigated for $\mathrm{CaO} \mathrm{CeO}_{2}$ (Table 6). Decreasing the amount of the catalyst from 3 to $1 \% \mathrm{w} / \mathrm{w}$ (catalyst/oil), a decrease of the conversion of bio-oil into FAMEs was observed, while the selectivity in the conversion of triglycerides 
and FFA remained almost the same. In such

concentration

is

linear.

interval the trend conversion vs catalyst

Table 6: Effect of the different weight ratio catalyst/oil in the trans-esterification reaction for the production of biodiesel

\begin{tabular}{|c|c|c|c|c|c|}
\hline \multirow{2}{*}{ Entry } & \multirow{2}{*}{$\begin{array}{c}\text { \% Weight ratio } \\
\text { Catalyst/Oil }\end{array}$} & \multirow{2}{*}{$\begin{array}{c}\text { \% Yield of } \\
\text { FAMEs }\end{array}$} & \multicolumn{2}{|c|}{ \% Conversion } & \multirow{2}{*}{$\begin{array}{c}\text { Ratio conversion } \\
\text { TG/FFA }\end{array}$} \\
& & TG & FFA & 1.03 \\
\hline 1 & 3 & 95.62 & 100 & 96.36 & 1.08 \\
\hline 2 & 2 & 66.48 & 82.78 & 76.65 & 1.14 \\
\hline 3 & 1 & 37.80 & 64.53 & 56.60 & 4.55 \\
\hline
\end{tabular}

It is worth to note that lowering the catalyst concentration below $1 \%$ towards $0 \%$ (catalyst absent) such linearity is lost. In fact, the experimental conversion of FAMEs and FFAs in absence of catalyst (Entry 4, Table 6) is not aligned with the data reported in Entries 1-3. Noteworthy, the pure thermal conversion of TGs is higher than the esterification of FFAs. Entry 4 shows that at zero catalyst only $5.67 \%$ of FFA is converted into FAMEs versus $25.80 \%$ of TG. Such trend is also demonstrated by the ratio conversion TG/FFA that increases by lowering the amount of catalyst.

It is of interest to analyse the effect of the composition of the ternary oxides (Entries 11 and 13 in Table 4) on the conversion of lipids and FFAs. While the oxide $12 \mathrm{CaO} \quad 7 \mathrm{Al}_{2} \mathrm{O}_{3}$ $3 \mathrm{CeO}_{2}$ has a poor activity towards the methylation of FFAs, oxides $12 \mathrm{CaO} 7 \mathrm{Al}_{2} \mathrm{O}_{3}$ $12 \mathrm{CeO}_{2}$, is more efficient towards FFAs and less towards lipids. The oxide $12 \mathrm{CaO} 7 \mathrm{Al}_{2} \mathrm{O}_{3}$
$7 \mathrm{CeO}_{2}$, is the most effective and efficient catalyst. (Aresta et al., 2013)

\section{Recovery and Re-Use of the Catalyst in the Conversion of Bio-Oil into FAMEs}

$\mathrm{CaO} \mathrm{CeO}_{2}$ and $12 \mathrm{CaO} \quad 7 \mathrm{Al}_{2} \mathrm{O}_{3} \quad 7 \mathrm{CeO}_{2}$ were used in re-cycling tests. In detail, after a reaction cycle, the catalyst was recovered by filtration and then treated following two different procedures: i) washing the solid with dry methanol followed by drying under vacuum for $3 \mathrm{~h}$ at $300 \mathrm{~K}$, and ii) calcining the catalyst again at $823 \mathrm{~K}$. Table 7 shows the results obtained. In both cases a clear deactivation of the catalyst $\mathrm{CaO} \mathrm{CeO}_{2}$ was observed due to the release of $\mathrm{CaO}$ in the liquid phase as determined by EDX analyses. In subsequent cycles, the content of $\mathrm{CaO}$ in the catalysts was decreased more and more making them less efficient towards lipids conversion. (Entries 2 and 3)

Table 7: Activity of recycled mixed oxide Ca/Ce (molar ratio 1:1) using two different methodologies for the recovery

\begin{tabular}{|c|c|c|c|c|c|c|}
\hline \multirow{2}{*}{} & \multicolumn{5}{|c|}{ \% Composition of the organic phase } & \multirow{2}{*}{ Sap. matter } \\
\cline { 2 - 7 } & FAMEs & MG & DG & TG & FFA & \\
\hline Starting Biooil & 0 & 1.24 & 5.83 & 72.92 & 18.68 & 98.67 \\
\hline $\mathbf{1}^{\circ} \mathbf{C y c l e}$ of reaction & 95.62 & 0.91 & 0.02 & 0 & 0.68 & 97.23 \\
\hline $\begin{array}{c}\mathbf{2}^{\circ} \mathbf{C y c l e} \\
\text { (dried 3 h under }\end{array}$ & 26.43 & 6.79 & 15.14 & 37.93 & 11.31 & 97.60 \\
\hline
\end{tabular}

Angela Dibenedetto, Antonella Angelini, Antonella Colucci, Luigi di Bitonto, Carlo Pastore, Brunella Maria Aresta, Cinzia Giannini and Roberto Comparelli (2016), International Journal of Renewable Energy and Biofuels, DOI: 10.5171/2016.204112 


\begin{tabular}{|c|c|c|c|c|c|c|}
\hline vacuum) & & & & & & \\
\hline $\begin{array}{c}\mathbf{2}^{\circ} \text { Cycle } \\
\text { (calcined 3 h at 823 K) }\end{array}$ & 17.98 & 4.57 & 14.26 & 46.78 & 13.56 & 97.15 \\
\hline
\end{tabular}

Conversely, when $12 \mathrm{CaO} 7 \mathrm{Al}_{2} \mathrm{O}_{3} 7 \mathrm{CeO}_{2}$ was used no release of $\mathrm{CaO}$ was observed and by simply washing the recovered catalyst with dry methanol and drying under vacuum it was possible to have an active catalyst for many cycles without any loss of activity (Table 8).
The presence of aluminium improves the stability of the calcium-cerium oxide by acting on the surface increasing the relevant resistance. Such beneficial influence on the catalysts has also been encountered in other catalytic applications (Aresta et al., 2010).

Table 8: Recycling of $12 \mathrm{CaO} 7 \mathrm{Al}_{2} \mathrm{O}_{3} 7 \mathrm{CeO}_{2}$ in the trans-esterification of bio-oil

\begin{tabular}{|c|c|c|c|c|c|}
\hline \multirow{2}{*}{ Cycle } & \multicolumn{4}{|c|}{ \% Composition of the organic phase } & \multirow{2}{*}{ Saponifiable Matter } \\
\cline { 2 - 5 } & FAMEs & MG & DG & TG & \\
\hline 1 & 97.96 & 0.067 & 0.002 & 0.008 & 98.04 \\
\hline 2 & 96.65 & 0.076 & 0.003 & 0.020 & 96.75 \\
\hline 3 & 96.29 & 0.062 & 0.001 & 0.011 & 96.36 \\
\hline 4 & 96.05 & 0.065 & 0.002 & 0.019 & 96.14 \\
\hline 5 & 96.51 & 0.060 & 0.002 & 0.021 & 96.59 \\
\hline
\end{tabular}

The results above demonstrate that the use of mixed oxides is a good strategy for the conversion of bio-oil (lipids and FFAs) in one pot into FAMEs with EU specification. It is worth to add that, contrarily to what observed using only $\mathrm{CaO}$, that is easily soluble in water and is not recoverable, the mixed oxides are much more resistant to water and to mechanic stress and result easily recoverable by simple filtration with a good capacity of re-use.

\section{Conclusions}

Our LCA studies applied to actual biofuels production from both seaweeds and microalgae (Aresta et al., 2005) helped us to identify weak points and strategies that may improve the economic value of such biomass. Therefore, we have investigated routes that may reduce the energetic and material costs in the production of biofuels. We have applied our knowledge to down-stream processes and found a low energy route to the simultaneous trans-esterification of lipids and esterification of FFAs with substantial improvement of the quality of bio-glycerol (low water and salts content) that can be used either for producing dihydrogen (Aresta and Dibenedetto, 2009; Dibenedetto et al., 2011) to be used in the hydrogenation of PUFAs for the production of good quality biodiesel or the synthesis of other chemicals that increase the economic value of the biomass. The one-pot trans-esterification of lipids and esterification of FFAs contributes to lower the operational cost of production of biodiesel from aquatic biomass. The new mixed-oxides catalysts used in this work are quite adaptable to convert bio-oils of different composition lipids-FFAs. A further improvement is represented by the catalytic extraction that avoids the preliminary extraction of bio-oil and produces FAMEs and glycerol quite pure for further applications. The catalyst $12 \mathrm{CaO} 7 \mathrm{Al}_{2} \mathrm{O}_{3} 7 \mathrm{CeO}_{2}$, is active especially in the conversion of bio oils with high FFAs content. It can be easily prepared by HEM and calcined at $823 \mathrm{~K}$ that reduced the environmental impact of catalyst 
preparation. It is easily recovered and can be re-used several times reducing the environmental impact of the catalyst disposal. The fact that the whole process does not use water is another quite positive aspect, as water use and processing is a quite sensitive parameter in industrial processes. As an additional benefit, bio-glycerol produced in this way is salt-free and waterfree, that reduces the need of costly and high energy purification techniques, making it more easily usable in further conversion technologies such as the biotechnological conversion into added value chemicals and monomers for polymers (e.g. 1,3propandiol), an application that is salt

\section{References}

1.Aranda, D.A.G., Gonçalves, J.A., Peres, J.S., Ramos, A.L.D., Ribeiro de Melo Jr, C.A., Antunes, O.A.C., Furtado, N.C, Taft, C. A. (2009) "The use of acids, niobium oxide, and zeolite catalysts for esterification reactions," Journal of Physical Organic Chemistry, 22 (7) 709-716.

2.Aresta, M. and Dibenedetto, A. (2009) "Energy from organic waste: influence of the process parameters on the production of methane and hydrogen. In P. Barbaro, C. Bianchini (Eds.) Catalysis for Sustainable Energy Production, Wiley-VCH, Weinheim, 271-284.

3.Aresta, M., Dibenedetto, A., Angelini, A., Pastore, C., di Bitondo, L. (2013) "Catalizzatori per la produzione di biodiesel da bio-oli," Patent Application MI2013A001730.

4.Aresta, M., Dibenedetto, A. and Barberio, G. (2005) "Utilization of macro-algae for enhanced $\mathrm{CO}_{2}$ fixation and biofuels production: Development of a computing software for an LCA study," Fuel Processing Technology, 86 (14-15) 1679-1693.

5.Aresta, M., Dibenedetto, A., Pastore, C., Angelini, A., Aresta, B. and Papai I. (2010) "Influence of $\mathrm{Al}_{2} \mathrm{O}_{3}$ on the performance of sensitive. The excess methanol used in the conversion of lipids and FFAs is not wasted as it can be easily recovered and re-used.

\section{Acknowledgment}

We wish to thank Prof. M. Aresta for fruitful discussions; the Apulian Region for the financial support to Project VALBIOR and the purchase of equipment and for a grant to $\mathrm{CP}$, and PON 01966 for partial financial contribution.

This paper was presented at the "Hartenergy Workshop" on Algae, Berlin, June 8, 2011 within the European Biomass Conference.

$\mathrm{CeO}_{2}$ used as catalyst in the direct carboxylation of methanol to dimethylcarbonate and the elucidation of the reaction mechanism," Journal of Catalysis, $269 \quad$ (1) 44-52.

6.Aresta, M., Dibenedetto, A., Carone, M., Colonna, T., and Fragale, C (2005) "Production of biodiesel from macroalgae by supercritical $\mathrm{CO}_{2} \quad$ extraction and thermochemical liquefaction" Environmental Chemistry Letters, 3 (3)136-139.

7.Bernhard Russbueldt, M.E. and Wolfgang Hoelderich F (2010) "New rare earth oxide catalysts for the transesterification of triglycerides with methanol resulting in biodiesel and pure glycerol," Journal of Catalysis 271 (2) 290-304.

8.Demirbas, A. (2008) "Biofuels sources, biofuel policy, biofuel economy and global biofuel projections," Energy Conversion and Management, 49: 2106-2116.

9.Demirbas, A. (2009) "Production of Biodiesel from Algae Oils," Energy Sources, Part A: Recovery, Utilization, and Environmental Effects, 31: 163-168.

10.Demirbas, A.H. and Demirbas, I. (2007) "Importance of rural bioenergy for developing countries," Energy Conversion Management, 48: 2386-2398.

11.Dibenedetto, A. (2011) "The potential of

Angela Dibenedetto, Antonella Angelini, Antonella Colucci, Luigi di Bitonto, Carlo Pastore, Brunella Maria Aresta, Cinzia Giannini and Roberto Comparelli (2016), International Journal of Renewable Energy and Biofuels, DOI: 10.5171/2016.204112 
aquatic biomass for carbon dioxide enhanced fixation and energy production," Greenhouse Gas Science and Technology, 1 (1) 58-71.

12.Dibenedetto, A., Angelini, A., Aresta, M. and Nocito, F.(2011) "Converting wastes into added value products: from glycerol to glycerol carbonate, glycidol and epichlorohydrin using environmentally friendly synthetic routes," Tetrahedron, 67 (6)1308-1313.

13.Dibenedetto, A., Aresta, M., Angelini, A., Ethiraj, J. and Aresta, B.M. (2012) "Synthesis, characterization, and use of $\mathrm{NbV} / \mathrm{CeIV}$-Mixed Oxides in the direct carboxylation of ethanol by using pervaporation membranes for water removal," Chemistry - A European Journal, 18 (33) 10324-10334.

14.Dibenedetto, A., Pastore, C., di Bitonto, L. and Colucci, A. (2011) "Bifunctional catalysts: tunable and efficient agents for the simultaneous transesterification of lipids and esterification of free fatty acids from bio-oils" 19th European Biomass Conference and Exhibition from research to industry and markets, DVD, Ed. by ETA. ISBN: 10:8889407557, ISBN: 13:978-8889407554.

EN 14105:2011 Fat and oil derivatives Fatty Acid Methyl Esters (FAME) Determination of free and total glycerol and mono-, di-, tri-glyceride content.

15.Ettarh, C. and Galwey, A.K. (1996) "A kinetic and mechanistic study of the thermal decomposition of calcium nitrate," Thermochimica Acta, 288 (1-2) 203-219.

16.Ferrer, C.B., Esclapez, S.P., Castelló, D.L and López, A.B. (2010) "Relationship between surface area and crystal size of pure and doped cerium oxides," Journal of Rare Earths, 28 (5) 647-653.

17.Helwani, Z., Othman, M.R., Aziz, N., Kim, J. and Fernando, W.J.N. (2009) "Solid heterogeneous catalysts for transesterification of triglycerides with methanol: A review," Applied Catalysis A:
General, 363: 1-10.

18.Jacobson, K., Gopinath, R., Meher, L.C. and Dalai, A.K. (2008) "Solid acid catalyzed biodiesel production from waste cooking oil," Applied Catalysis B, 85 (1-2) 86-91.

19.Knothe, G., Van Gerpen, J. and Krahl, J. (2005) The Biodiesel Handbook. AOCS, Champaign,

IL.

20.Mata, T.M., Martins, A.A. and Caetano, N.S. (2010) "Microalgae for biodiesel production and other applications: a review," Renewable and Sustainable Energy Reviews, 14 (1) 217232.

21.Matsuishi, S., Hayashi, K., Hirano, M., Tanaka, I. and Hosono, H. (2004) "Superoxide Ion Encaged in Nanoporous Crystal $12 \mathrm{CaO} \cdot 7 \mathrm{Al}_{2} \mathrm{O}_{3}$ Studied by Continuous Wave and Pulsed Electron Paramagnetic Resonance," The Journal of Physical Chemistry B, 108 (48) 18557-18568.

22.Özbay, N., Oktar, N. and Tapan, N.A. (2008) "Esterification of free fatty acids in waste cooking oils (WCO): role of ionexchange resins," Fuel, 87 (10-11) 17891798.

23.Patil, D., Gude, V.G., Mannarswamy, A.,Cooke, P., Munson-McGee, S., Nirmalakhandan, N., Lammers, P., and Deng, S. (2011) "Optimization of microwaveassisted transesterification of dry algal biomass using response surface methodology," Bioresource Technology, 102 (2) 1399-1405.

24.Ríos, S.D., Castañeda, J., Torras, C., Farriol, X. and Salvadó, J. (2013) "Lipid extraction methods from microalgal biomass harvested by two different paths: Screening studies toward biodiesel production," Bioresource Technology, 133: 378-388.

25.Scott, S.A., Davey, M.P., Dennis, J.S., Horst, I., Howe, C.J., Lea-Smith, D.J. and Smith, A.G. (2010) "Biodiesel from algae: challenges and prospects," Current Opinion in Biotechnology, 21: 277-286. 
26.Sharma, Y.C., Singh, B. and Upadhyay, S.N. (2008) "Advancements in development and characterization of biodiesel: A review," Fuel, 87: 2355-2373.

27.Singh, N.K. and Dhar, D.W. (2011) "Microalgae as second generation biofuel. A review," Agronomy for Sustainable Development, 31(4) 605-629.

Sivasamy, A., Cheah, K. Y., Fornasiero, P., Kemausuor, F., Zinoviev, S. and Miertus, S. (2009) "Catalytic applications in the production of biodiesel from vegetable oils," ChemSusChem, 2 2: 278-300.

28.The American Oil Chemists' Society, Preparation of Methyl Esters of Fatty Acids (1997) Official Methods and Recommended Practices of the AOCS, Official Method Ce 2$66 . \quad$ In Champaign, IL.
UNI EN 14774-2:2010. Solid biofuels -
Methods for the determination of moisture content - Oven dry method - Part 2: Total moisture - Simplified method.

30.UNI EN 14775:2010. Solid biofuels Method for the determination of ash content.

31.UNI EN 14918:2010. Solid Biofuels Method for the determination of calorific value.

32.Vinatoru, M., Toma, M., Radu, O., Filip, P.I., Lazurca, D. and Mason T.J. (1997) "The use of ultrasound for the extraction of bioactive principles from plant materials," Ultrasonics Sonochemistry, 4 (2) 135-139.

33.Zabeti, M., Ashri Wan Daud, W. and Aroua, M.K.(2009) "Activity of solid catalysts for biodiesel production: A review," Fuel Processing Technology, 90 (6) 770-777.

Angela Dibenedetto, Antonella Angelini, Antonella Colucci, Luigi di Bitonto, Carlo Pastore, Brunella Maria Aresta, Cinzia Giannini and Roberto Comparelli (2016), International Journal of Renewable Energy and Biofuels, DOI: 10.5171/2016.204112 